\title{
Non-invasive time-lapsed monitoring and quantification of engineered bone-like tissue
}

\section{Journal Article}

\section{Author(s):}

Hagenmüller, Henri; Hofmann, Sandra; Kohler, Thomas; Merkle, Hans P.; Kaplan, David L.; Vunjak-Novakovic, Gordana; Müller, Ralph (D); Meinel, Lorenz

Publication date:

2007

Permanent link:

https://doi.org/10.3929/ethz-b-000003704

Rights / license:

In Copyright - Non-Commercial Use Permitted

Originally published in:

Annals of Biomedical Engineering 35(10), https://doi.org/10.1007/s10439-007-9338-2 


\title{
Non-Invasive Time-Lapsed Monitoring and Quantification of Engineered Bone-Like Tissue
}

\author{
Henri Hagenmüller, ${ }^{1,2}$ Sandra Hofmann, ${ }^{2}$ Thomas Kohler, ${ }^{1}$ Hans P. Merkle, ${ }^{2}$ David L. Kaplan, ${ }^{3}$ \\ Gordana Vunjak-Novakovic, ${ }^{4}$ Ralph Müller, ${ }^{1}$ and Lorenz Meinel ${ }^{2,3}$ \\ ${ }^{1}$ Institute for Biomechanics, ETH Zurich, 8093 Zurich, Switzerland; ${ }^{2}$ Institute of Pharmaceutical Sciences, ETH Zurich, 8093 \\ Zurich, Switzerland; ${ }^{3}$ Department of Biomedical Engineering, Tufts University, Medford, MA 02155, USA; and ${ }^{4}$ Department of \\ Biomedical Engineering, Columbia University, New York, NY 10027, USA
}

(Received 31 August 2006; accepted 23 May 2007; published online 2 June 2007)

\begin{abstract}
The formation of bone-like tissue from human mesenchymal stem cells (hMSC) cultured in osteogenic medium on silk fibroin scaffolds was monitored and quantified over 44 days in culture using non-invasive time-lapsed micro-computed tomography $(\mu \mathrm{CT})$. Each construct was imaged nine times in situ. From $\mu \mathrm{CT}$ imaging, detailed morphometrical data on bone volume density, surface-tovolume ratio, trabecular thickness, trabecular spacing, and the structure model index and tissue mineral density were obtained. $\mu \mathrm{CT}$ irradiation did not impact the osteogenic performance of hMSCs based on DNA content, alkaline phosphatase activity, and calcium deposition when compared to non-exposed control samples. Bone-like tissue formation initiated at day 10 of the culture with the deposition of small mineralized clusters. Tissue mineral density increased linearly over time. The surface-to-volume ratio of the bone-like tissues converged asymptotically to $26 \mathrm{~mm}^{-1}$. Although in vitro formation of bone-like tissue started from clusters, the overall bone volume was not predictable from the time, number, and size of initially formed bone-like clusters. Based on microstructural analysis, the morphometry of the tissueengineered constructs was found to be in the range of human trabecular bone. In future studies, non-invasive, time-lapsed monitoring may enable researchers to culture tissues in vitro, right until the development of a desired morphology is accomplished. Our data demonstrate the feasibility of qualitatively and quantitatively detailing the spatial and temporal mineralization of bone-like tissue formation in tissue engineering.
\end{abstract}

Keywords-Tissue engineering, Bone, Micro-computed tomography, Human mesenchymal stem cells, Silk, Scaffold.

\section{INTRODUCTION}

Bone tissue engineering is a field of increasing interest in orthopedics. ${ }^{1,12,20,33}$ In particular the use of

Address correspondence to Lorenz Meinel, Institute of Pharmaceutical Sciences, HCI J 392.4, ETH Zurich, Wolfgang-Pauli-Str. 10, 8093 Zurich, Switzerland. Electronic mail: lorenz.meinel@pharma. ethz.ch in vitro-engineered bone tissues offers the opportunity to substitute malfunctioning, injured, or diseased tissue in patients suffering from degenerative diseases or tumors. Tissue engineering of skeletal tissues generally requires at least three elements: (i) three-dimensional scaffolds, (ii) cells, and (iii) bioreactors with appropriate media, to form tissues such as bone, cartilage, or even osteochondral plugs. 5,7,19,26,32,33 Engineered constructs have the potential to replace compromised or missing host tissue or to serve for extended in vitro studies of bone formation in well-controlled settings.

Mesenchymal stem cells derived from human bone marrow (hMSC) are a well-known cell source to engineer autologous bone tissues. They can be expanded to large cell numbers in an undifferentiated state and, when exposed to the appropriate extrinsic signals, selectively differentiate along mesenchymal lineages, including cartilage and bone. ${ }^{25}$ Scaffolds prepared from silk fibroin (SF) have shown promising results as substrates for in vitro and in vivo culture of bone-like tissue. The quality of the bone-like tissue was confirmed by biochemical assays, histology, gene expression assays, X-ray diffraction analysis, and $\mu \mathrm{CT} .{ }^{15,17,20} \mathrm{SF}$ scaffolds demonstrated equivalent or better biocompatibility than type I collagen scaffolds, and distinguished mechanical strength and mechanical integrity as compared to other commonly used degradable polymeric biomaterials. ${ }^{17,19,20}$ Furthermore, the degradation of SF scaffolds is slow, a prerequisite for the present study aiming at imaging and quantifying bone-like tissue formation on a stable, yet degradable system. Faster degradation rate as observed for type I collagen would impact the ordered formation of bone-like tissues and, therefore, the demonstration of feasibility for timelapsed bone visualization sought in the present study, due to disintegration of the substrate during cell growth and tissue formation. To seed cells on SF scaffolds Matrigel was chosen. Matrigel is a solubilized basement 
membrane matrix which supports the growth and differentiation of different cell types but does not contain osteogenic inducers. ${ }^{2}$ In previous studies the combination of Matrigel-based seeding and SF scaffolds proved to be successful for the settlement of hMSC and the subsequent deposition of bone-like tissue. ${ }^{11}$

At present, assessments of in vitro-engineered tissue quality and quantity rely on destructive methods, thereby terminating cultures and necessitating multiple samples for adequate statistical analysis. Obviously this requirement also hinders the understanding of dynamic tissue formation processes for individual specimens and information is generally taken from pooled samples forming a treatment group. ${ }^{19,20,31,35}$ Future clinical supply scenarios will require quality assessment of the selected implant, rather than retrospective data obtained from destructive analysis or from pooled samples as is currently the state of the art. Automated, well-controlled bioreactors can potentially be coupled to non-invasive imaging setups, thereby providing the necessary information of tissue quality and formation during culture for implants. ${ }^{16}$

The goal of this study was to monitor non-invasively and temporally the development of bone-like tissue, engineered from hMSCs, by the integral use of micro-computed tomography $(\mu \mathrm{CT})$. Novel illustrations of growing bone-like tissue and individual quantification concerning bone volume density, surface-to-volume ratio, trabecular thickness, trabecular spacing, the structure model index, and tissue mineral density of the constructs were provided. Hence, the formation of engineered bone-like tissue from hMSCs on SF scaffolds could be directly compared to physiological values. In the future, this or similar imaging techniques should facilitate the assessment and selection of constructs from a pool of autologous-engineered implants based on qualitative and quantitative yet non-destructive imaging regimens.

\section{MATERIALS AND METHODS}

\section{Materials}

Cocoons from Bombyx mori were kindly provided by Trudel Inc. (Zurich, Switzerland). Bone morphogenetic protein-2 (BMP-2) was kindly provided by Wyeth (Madison, $\mathrm{NJ})$. Sodium Carbonate $\left(\mathrm{Na}_{2} \mathrm{CO}_{3}\right)$, Lithium Bromide ( $\mathrm{LiBr}$ ), and 1,1,1,3,3,3-Hexafluoroisopropanol (HFIP) were from Fluka (Buchs, Switzerland). Bone marrow was from Cambrex (\#1M-125, Walkersville, MD). Ascorbic acid-2-phosphate, dexamethasone, B-glycerolphosphate, and alkaline phosphatase (AP) assay were from Sigma-Aldrich (St. Louis, MO). Trichloroacetic acid was from Haenseler
(Herisau, Switzerland). Calcium quantification assay was from Rolf Greiner Biochemica (\#G210117, Flacht, Germany). Antibodies CD31-PE, CD34-APC, CD44FITC, CD105-FITC, $\alpha_{\mathrm{V}} \beta_{\mathrm{I}^{-}}$-FITC, and Matrigel were from BD Biosciences (San Jose, CA). Triton X-100 was from Biospec Products (Bartlesville, OK). All other substances were obtained from Invitrogen (Carlsbad, CA).

\section{Scaffold Production}

Purified silkworm fibroin was prepared and formed into porous scaffolds as previously described. ${ }^{23} \mathrm{In}$ brief, cocoons from B. mori were boiled for $1 \mathrm{~h}$ in an aqueous solution of $0.02 \mathrm{M} \mathrm{Na}_{2} \mathrm{CO}_{3}$, and rinsed with water to extract sericin and other contaminating proteins. Purified SF was solubilized in $9 \mathrm{M} \mathrm{LiBr}$ solution and dialyzed (Pierce 3500 MWCO, Woburn, MA) against water. The water was exchanged five times in $72 \mathrm{~h}$ resulting in a SF concentration of approximately $3 \%(\mathrm{w} / \mathrm{v})$. The SF solution was lyophilized (Christ, Osterode, Germany) and afterwards dissolved in HFIP resulting in a $17 \%(\mathrm{w} / \mathrm{v})$ solution. Granular $\mathrm{NaCl}$ was characterized for size using a sieving tower (Retsch, Arlesheim, Switzerland). The range of sizes of the employed porogen $\mathrm{NaCl}$ was $224-300 \mu \mathrm{m}$. For each scaffold, $\mathrm{NaCl}$ was weighed in a Teflon container and $\mathrm{SF} / \mathrm{HFIP}$ solution was added at a ratio of $20: 1(\mathrm{NaCl} /$ $\mathrm{SF}$ ). HFIP was allowed to evaporate for 2 days and the $\mathrm{NaCl} /$ silk blocks were immersed in $90 \%(\mathrm{v} / \mathrm{v})$ methanol for $30 \mathrm{~min}$ to induce a protein conformational transition to $\beta$-sheet. ${ }^{23}$ The blocks were removed, dried, and $\mathrm{NaCl}$ was extracted in water for 2 days. Disk-shaped scaffolds $(5 \mathrm{~mm}$ diameter, $1 \mathrm{~mm}$ thick) were prepared using a dermal punch and autoclaved.

\section{Cell Isolation and Expansion}

Cell isolation was performed as previously described. ${ }^{19}$ Briefly, samples of bone marrow were diluted in Roswell Park Memorial Institute (RPMI) medium supplemented with $5 \%$ fetal bovine serum (FBS). The cells were centrifuged at $300 \times g$ for $10 \mathrm{~min}$. Pelleted cells were resuspended in expansion medium (Dulbecco's Modified Eagle Medium (DMEM), 10\% FBS, penicillin-streptomycin, fungizone, $1 \%$ non-essential amino acids (NEAA), $1 \mathrm{ng} / \mathrm{mL}$ basic fibroblast growth factor (bFGF)) and seeded in $175-\mathrm{cm}^{2}$ flasks (Nunc, Roskilde, Denmark) at a density of $5 \times 10^{4}$ cells $/ \mathrm{cm}^{2}$. The adherent cells were allowed to reach $80 \%$ confluence (12-17 days for the first passage). Cells were trypsinized and replated every 6-8 days at $80 \%$ confluence. The second passage (P2) cells were used for tissue culture. 
The hMSC were characterized with respect to (i) the expression of surface antigens and (ii) the ability to selectively differentiate along the chondrogenic and osteogenic lineages. The expression of the following five surface antigens was characterized by flow cytometry analysis (BD Biosciences FACScalibur, San Jose, CA), as described previously ${ }^{19}$ : CD31 (PECAM-1/endothelial cells), CD34 (sialomucin/hematopoietic precursors), CD44 (hyaluronic acid receptor/hematopoietic cells and MSC), CD105 (endoglin/endothelial cells and MSC), and $\alpha_{\mathrm{V}} \beta_{\mathrm{I}}$ (immunocells and MSC). To assess the potential of hMSC for osteogenic and chondrogenic differentiation, the cells were cultured in 12-well plates (TPP, Trasadingen, Switzerland) as micro-mass cultures ( 5 drops of $15 \mu \mathrm{L}$ of $2 \times 10^{7}$ cells $/ \mathrm{mL}$ per well) in either control medium (DMEM supplemented with $10 \%$ FBS, $1 \%$ penicillin-streptomycin, $0.2 \%$ fungizone, $50 \mu \mathrm{g} / \mathrm{mL}$ ascorbic acid-2-phosphate, and $10 \mathrm{nM}$ dexamethasone) or osteogenic medium (control medium supplemented with $7 \mathrm{mM}$ B-glycerolphosphate, and $1 \mu \mathrm{g} / \mathrm{mL}$ BMP-2) or chondrogenic medium (control medium supplemented with $1 \%$ NEAA, $5 \mu \mathrm{g} / \mathrm{mL}$ insulin, and $5 \mathrm{ng} / \mathrm{mL}$ transforming growth factor beta $\left(\right.$ TGF- $\left.\beta_{1}\right)$ ). Medium was exchanged three times per week. After 2 weeks of culture the amounts of DNA, AP activity, glycosaminoglycans (GAG), and calcium were measured, as described previously. ${ }^{19}$

\section{Tissue Culture}

For cultivation on $\mathrm{SF}$ scaffolds $(5 \mathrm{~mm}$ diameter $\times 1 \mathrm{~mm}$ thick disks), P2 hMSC were suspended in liquid Matrigel $\left(10^{6}\right.$ cells per scaffold in $10 \mu \mathrm{L}$ Matrigel) while working on ice to prevent gelation, and the suspension was seeded onto prewetted scaffolds (overnight incubation of scaffold in DMEM). Seeded constructs (in culture dishes, without added medium) were placed in an incubator at $37^{\circ} \mathrm{C}$ for $15 \mathrm{~min}$ to allow gel hardening before placement in the culture vials.

Custom culture vials from poly(ether imide) (PEI) were used to host the constructs during culture. These vials enabled tissue culture due to their biocompatibility, ${ }^{30}$ while also allowing sterile $\mu \mathrm{CT}$ imaging of the constructs in a fixed position. The constructs were cultured in the incubator and could be taken out of the incubator and transferred to the $\mu \mathrm{CT}$ (Scanco Medical $\mu \mathrm{CT} 40$, Bassersdorf, Switzerland) for imaging without disturbing the scaffold system. During the imaging process, the vials were completely closed to maintain sterility for approximately $1 \mathrm{~h}$, while gas exchange was provided during culture in the humidified incubator $\left(37{ }^{\circ} \mathrm{C}, 5 \% \mathrm{CO}_{2}\right)$. The constructs could be returned to the incubator after each $\mu \mathrm{CT}$ scan without terminating the culture. Five constructs were placed in each vial.
The samples were positioned at a distance of $9 \mathrm{~mm}$ to each other. To eliminate differences in environmental factors several samples were placed in each vial. Four vials were used for the biochemical assessment of the non-scanned control group, four vials were scanned from day 7 through day 28 and used for biochemical assessment of the scanned group, and three vials were scanned from day 7 through day 44 and used for $\mu \mathrm{CT}$ based morphology assessment. The vials were filled with $5 \mathrm{~mL}$ of osteogenic medium as detailed above and the medium was replaced three times per week for 44 days of cultivation. As demonstrated in earlier studies, using the same type of scaffolds, this formulation of osteogenic medium does not result in spontaneous precipitation of minerals. ${ }^{15,18}$

\section{Micro-Computed Tomography}

In situ $\mu \mathrm{CT}$ images were taken at days $7,10,14,17$, $21,24,28,37$, and 44 of the culture. Constructs were monitored with a $\mu \mathrm{CT}$ imaging system (Scanco Medical $\mu \mathrm{CT} 40$, Bassersdorf, Switzerland) providing an isotropic resolution of $36 \mu \mathrm{m}$. Energy was set to $40 \mathrm{kVp}$, integration time was $200 \mathrm{~ms}$, two-fold frame averaging was chosen. A constrained Gaussian filter was used to partly suppress noise. Mineralized tissue was segmented from non-mineralized tissue using a global thresholding procedure. ${ }^{29}$ All samples were processed by using the same filter width (1.2), filter support (1), and threshold $(20.7 \%$ of maximal image gray value corresponding to a hydroxyapatite density equivalent of $130 \mathrm{mgHA} / \mathrm{ccm}$ ). This threshold was chosen as it allowed the segmented images to best resemble the mineralized structures visible by eye from the gray value images.

Using direct microstructural bone analysis quantitative morphometry indices as known from human bone biopsy analysis were assessed ${ }^{9}$ : bone volume $(\mathrm{BV})$, bone volume density $(\mathrm{BV} / \mathrm{TV}$, where $\mathrm{TV}$ is the volume of the whole examined sample), bone surfaceto-volume ratio (BS/BV), trabecular thickness (Tb.Th), trabecular spacing (Tb.Sp), and structure model index (SMI, which estimates the plate-rod characteristic of a structure $^{10}$ ). For the assessment of tissue mineral density, the gray value images were correlated to calibrated gray values of hydroxyapatite phantoms provided by the $\mu \mathrm{CT}$ manufacturer. Therefore, a gray value in an image could be directly expressed as a hydroxyapatite density equivalent. Tissue mineral density was determined only within the segmented bone volume; all non-mineralized regions were excluded from the analysis and two voxels were peeled from the surface of the bone volume beforehand to exclude partial volume effects as recommended by the $\mu \mathrm{CT}$ manufacturer. 
Three-dimensional visualizations were generated using AVS/Express (Advanced Visual Systems, Waltham, MA) and in-house software. ${ }^{21,22}$ To visually monitor the growth of the bone-like tissue, the subsequence of images was superimposed and volumes imaged at different times were illustrated by different colors and degrees of transparency.

\section{Effect of $\mu C T$ Imaging on Cell Performance}

After 28 days of culture and $7 \mu \mathrm{CT}$ scans, samples from the imaged group were compared to samples from a non-imaged control group to check for a possible effect of the $\mu \mathrm{CT}$ irradiation on the tissue. This was based on biochemical analysis and on $\mu \mathrm{CT}$. For determination of DNA content, ten constructs per group were disintegrated in $0.1 \%$ Triton X-100 solution using steel balls and a minibead beater (Biospec Products, Bartlesville, OK). The content of each group was transferred to a new tube and centrifuged at $300 \times g$ for $10 \mathrm{~min}$ at $4{ }^{\circ} \mathrm{C}$. The resulting supernatant was used for the PicoGreen DNA quantification assay, according to the manufacturer's protocol. Aliquots from the same tubes were used to measure the AP activity using a commercially available assay based on conversion of $p$-nitrophenyl phosphate to $p$-nitrophenol. For determination of calcium content, ten constructs per group were disintegrated twice in $2 \times 0.5 \mathrm{~mL} 5 \%$ trichloroacetic acid using steel balls and a minibead beater. After centrifugation at $3000 \times g$ for $10 \mathrm{~min}$ at $4{ }^{\circ} \mathrm{C}$, the supernatant was assessed spectrophotometrically at $575 \mathrm{~nm}$ following the reaction with $o$-cresolphthalein complexone according to the manufacturer's protocol. For the $\mu \mathrm{CT}$ analysis of the formerly non-irradiated samples, samples were imaged at day 28 of culture and post-processed as described above. The parameters $\mathrm{BV} / \mathrm{TV}, \mathrm{BS} / \mathrm{BV}$, $\mathrm{SMI}, \mathrm{Tb} . \mathrm{Th}$, and Tb.Sp were used for comparison.

\section{Statistical Analysis}

Data are presented as mean \pm standard deviation and statistical analysis of data was performed by Student's $t$-test using Microsoft Excel. Values of $p \leq 0.05$ were considered significant, and $p \leq 0.01$ were considered highly significant.

\section{RESULTS}

\section{Characterization of $h M S C$}

Surface antigen expression demonstrated that the cells were positive for CD105, integrin $\alpha_{\mathrm{V}} \beta_{\mathrm{I}}$ and, to a lesser extent, CD44. Negative expression of surface antigens for CD31 and CD34 suggested the absence of cells of endothelial or hematopoietic origin.

Culture-expanded hMSC maintained their ability to selectively undergo chondrogenic and osteogenic differentiation, as assessed biochemically. Micro-mass cultures of P2 and P3 hMSC cultured for 2 weeks in osteogenic medium showed higher degrees of AP activity as compared to cells cultured in chondrogenic medium. Calcium deposition was observed in osteogenic medium, but not in control medium. GAG accumulation was strikingly higher in chondrogenic medium when compared to control medium. AP activity and the amounts of calcium and GAG in micro-mass cultures of $\mathrm{P} 2$ and $\mathrm{P} 3$ cells were comparable. Importantly, cultures of hMSC deposited chondrogenic markers only when cultured in chondrogenic medium and osteogenic markers only when cultured in osteogenic medium.

\section{Bone Volume and Bone Volume Density}

Trabecular bone-like tissue formation was observed with $\mu \mathrm{CT}$ (Figs. 1 and 2). BV increased over time with high standard deviations starting off at $0.04 \pm 0.04 \mathrm{~mm}^{3}$ at day 10 up to $3.8 \pm 2.5 \mathrm{~mm}^{3}$ at day 44 (Fig. 3a). For pooled samples, BV as a function of time followed an exponential pattern, with $B V(t[$ day $])=0.0046 e^{0.226 t} \mathrm{~mm}^{3}\left(R^{2}=96.8 \%\right)$ up to day 24 , followed by a linear deposition up to day 44 with $B V(t[$ day $])=(0.15 t-2.7) \mathrm{mm}^{3}\left(R^{2}=99.6 \%\right)$. Individual samples followed different growth trends over time, ranging from strictly linear patterns $\left(R^{2}=99.6 \%\right)$ to exponential patterns $\left(R^{2}=96.4 \%\right)$ over 44 days (Figs. 1c and 3a).

BV was visualized in superimposed maps as a function of time (BV after 14, 28, and 44 days are displayed in blue, green, and red, respectively; Fig. 2). Heterogeneity in BV was corroborated and BV after 44 days in culture was found to be non-predictable from BV at early time points $\left(R^{2}=7 \%\right.$ for linear regression between $\mathrm{BV}($ day 14$)$ and $\mathrm{BV}($ day 44$)$ ). Tissue formation originated from clusters at the outer scaffold rims and proceeded towards the scaffold center. Over time, continued formation of new bonelike tissue clusters was observed as indicated by red spots (end point day 44) in the cross-sectional and side view (Fig. 2). No signs of slowing of the osteogenic process were seen even at day 44 .

Since the volume of the whole examined samples (TV) did not vary within this study, the normalized index bone volume density (BV/TV) showed the same pattern as BV and is given for comparison (Fig. 3a). 

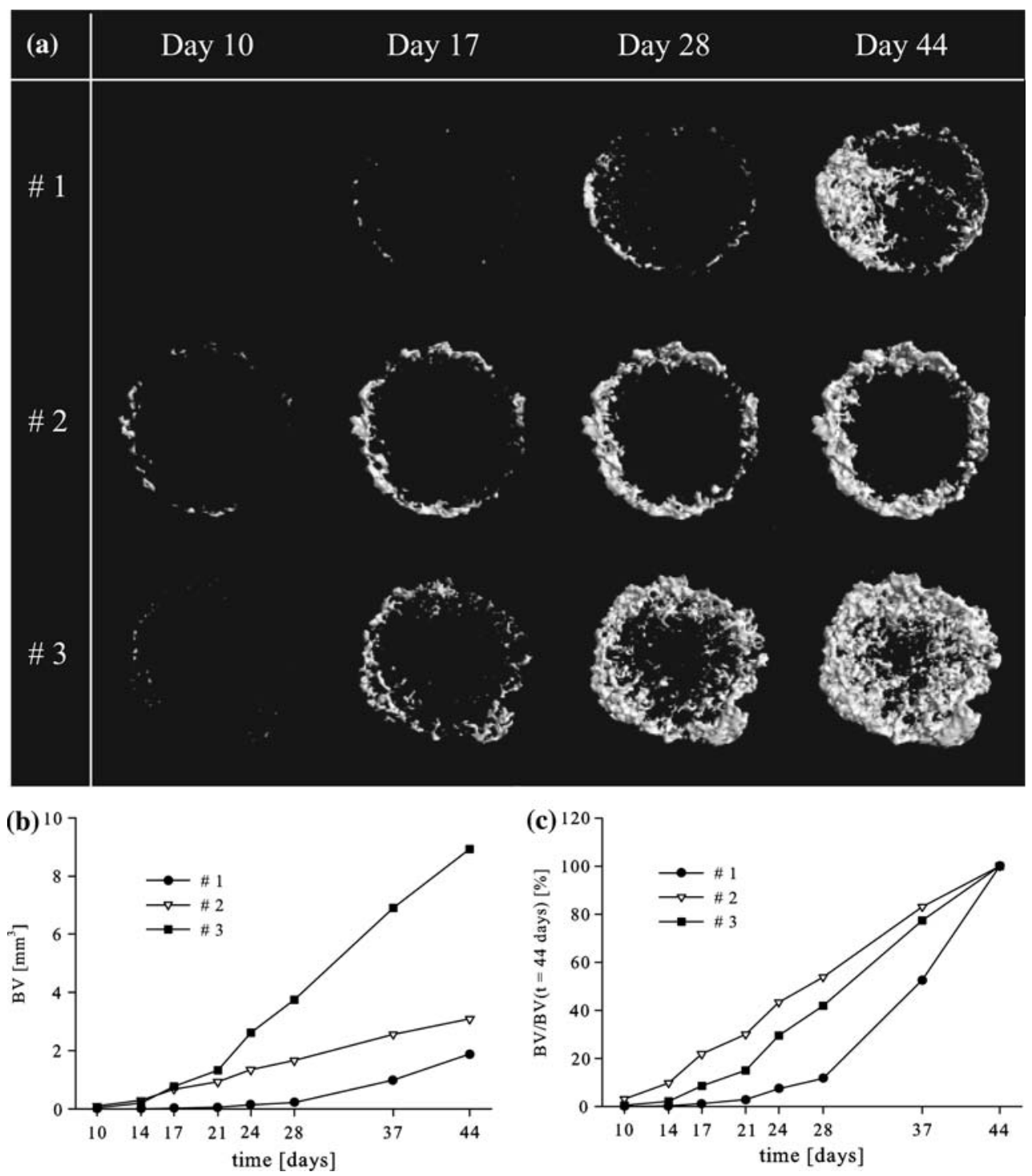

FIGURE 1. (a) Individual sample data showing 3D top view images of three representative samples at days 10 , 17,28 , and 44 , as imaged using $\mu \mathrm{CT}$, (b) corresponding bone volume over time, and (c) corresponding relative bone volume over time.

\section{Bone Surface-to-Volume Ratio}

A continuous decrease of the mean bone surface-tovolume ratio $(\mathrm{BS} / \mathrm{BV})$ was observed over time (from $80.0 \mathrm{~mm}^{-1}$ at day 10 to $26.1 \mathrm{~mm}^{-1}$ at day 44 ) (Fig. 3b). $\mathrm{BS} / \mathrm{BV}$ coefficient of variation declined over time, from $64 \%$ at day 10 to $21 \%$ at day 44 . Evidence was provided that all samples, regardless of the initial BS/BV value, asymptotically approached a final value of $26 \pm 5 \mathrm{~mm}^{-1}$ (Fig. 3b). The general trend for the pooled data followed an exponential pattern with $B S / B V(t$ [day] $)=90.8 e^{-0.031 t} \mathrm{~mm}^{-1}\left(R^{2}=90.1 \%\right)$. However, analysis of individual sample development from day 10 through day 44 revealed different patterns for different samples, ranging from linear $(B S / B V(t$ day $\left.])=(-0.9 t+61.6) \mathrm{mm}^{-1}, R^{2}=88.1 \%\right)$ to strictly exponential $\left(B S / B V(t[\right.$ day $])=158.7 e^{-0.042 t}$ $\left.\mathrm{mm}^{-1}, R^{2}=95.2 \%\right)$.

\section{Structure Model Index}

Over the culture period the mean SMI dropped from 3.18 to 2.59 (ideal spheres: $\mathrm{SMI}=4$, ideal rods: SMI $=3$, ideal plates: SMI = 0, Fig. 3c), suggesting structure development from sphere-like nodules towards more rod- and plate-like. For the development of SMI over time, no mathematical pattern could be found for pooled data. Regarding individual data, the curves of most samples followed a linear trend, while others were inconsistent and did not follow a general trend. 


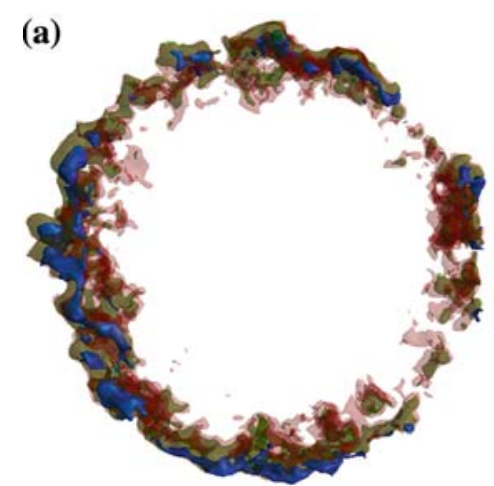

(c)

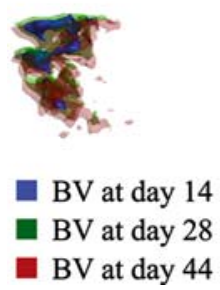

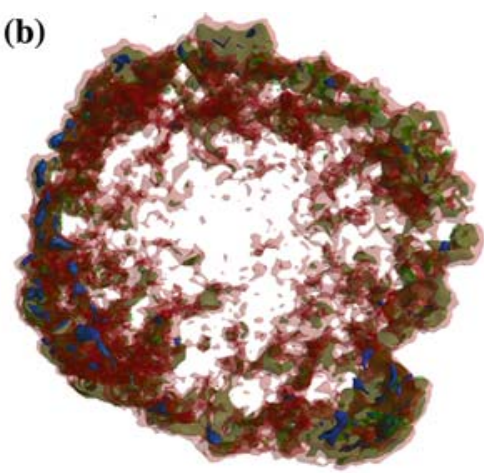

(d)
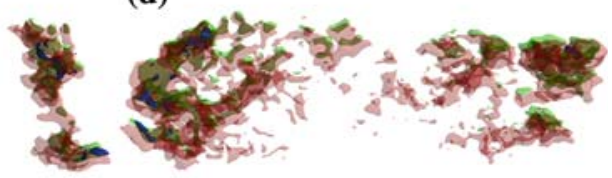

FIGURE 2. Superimposed 3D bone volumes of two representative samples illustrating the progression of bone-like tissue deposition: (a-b) Top views and (c-d) side views on corresponding center slices; blue = bone volume $(B V)$ at day 14 , green = BV at day 28 , red $=$ BV at day 44 , as imaged using $\mu \mathrm{CT}$.

\section{Trabecular Thickness and Trabecular Spacing}

Pooled data indicated a steady increase in trabecular thickness over the whole culture period from 0.072 to $0.146 \mathrm{~mm}$ (Fig. 3d). For pooled samples, Tb.Th as a function of time followed a logarithmic pattern, with $\operatorname{Tb} . T h(t[$ day $])=(0.058 \operatorname{Ln}(t)-0.078) \mathrm{mm}\left(R^{2}=98.7 \%\right)$. While individually most samples also followed a logarithmic pattern, data revealed an interim drop in trabecular thickness for 2 of the 11 samples. Mean trabecular spacing decreased from 1.58 to $0.94 \mathrm{~mm}$, while individual data showed a rather unsteady development of trabecular spacing for individual samples (Fig. 3e).

\section{Tissue Mineral Density}

Based on pooled data tissue mineral density increased linearly over time $\left(R^{2}=96 \%\right)$ following TissueMineralDensity $(t[$ day $])=(172+t) \mathrm{mgHA} / \mathrm{cm}^{3}$, as shown in Fig. 3f.

\section{Effect of $\mu C T$ Imaging on Cell Performance}

DNA content per scaffold of the non-irradiated control group $(94.6 \pm 50.3 \mu \mathrm{g}, n=10)$ and the irradiated group $(87.9 \pm 15.5 \mu \mathrm{g}, n=10)$ were not significantly different after 28 days of culture and seven repetitive $\mu \mathrm{CT}$-based imaging cycles (Fig. 4b). No significant irradiation effect was found for alkaline phosphatase activity per DNA (AP activity,
$0.38 \pm 0.19$ and $0.42 \pm 0.09$, respectively; $n=10$ ) or calcium deposition per scaffold $(235.4 \pm 77.5 \mu \mathrm{g}$ and $272.7 \pm 100.2 \mu \mathrm{g}$, respectively; $n=10$ ). Also morphometrical data achieved from $\mu \mathrm{CT}$ imaging did not reveal significant differences in cell performance due to multiple irradiation (Figs. $4 \mathrm{a}$ and $4 \mathrm{~b}$ ).

\section{DISCUSSION}

This study was based on the hypothesis that in vitro bone-like tissue formation can be visualized and quantified on hMSC-seeded SF scaffolds using $\mu \mathrm{CT}$ imaging. This is based on $\mu \mathrm{CT}$ imaging as an integral tool for the qualitative and quantitative evaluation of bone implants, using tissue engineering approaches. Moreover, this work was motivated by the need to provide feasibility data leading towards the development of an imaging interface, which can provide image-guided input parameters for future bioreactors. Feeding image-derived tissue information into algorithms may guide the continuous adaptation of medium composition, physical, and chemical stimuli in an automated and feedback mode to optimize the engineering of bone implants.

The surface antigen pattern of expanded cells, isolated from human bone marrow, were typical for hMSCs and demonstrated the cell's capacity to selectively differentiate along osteogenic and chondrogenic lineages, respectively. ${ }^{19,25}$ Based on this pattern of 

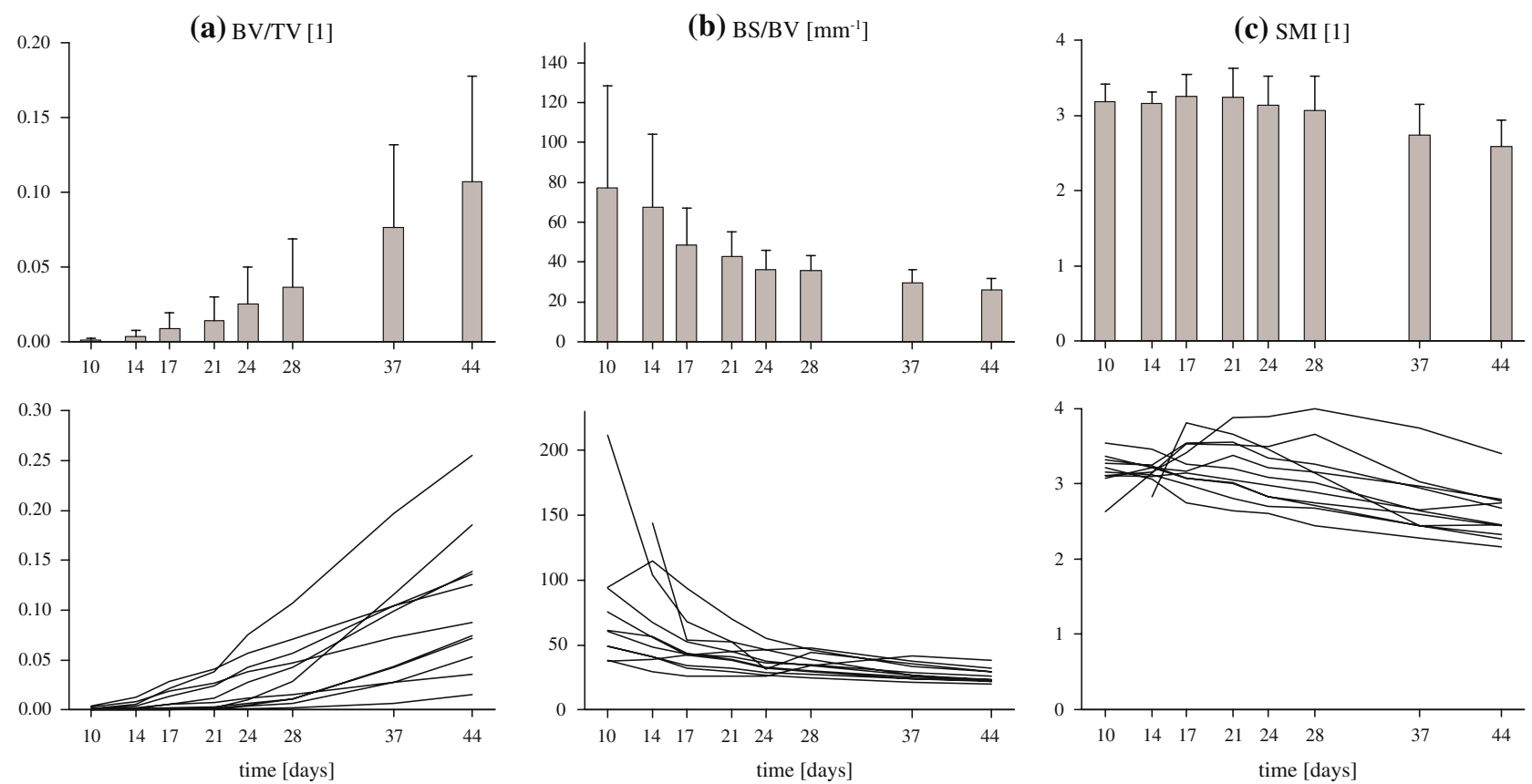

(d) Tb.Th $[\mathrm{mm}]$

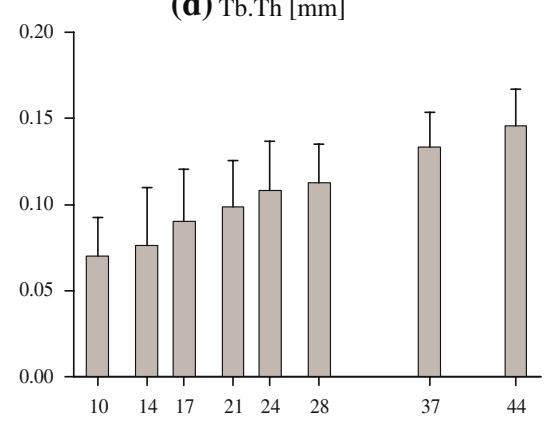

(e) Tb.Sp $[\mathrm{mm}]$

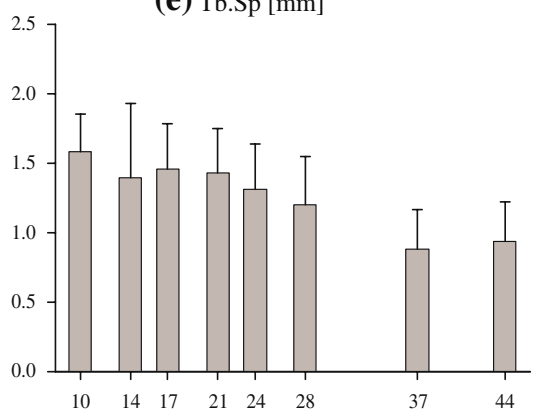

(f) $\mathrm{TMD}[\mathrm{mgHA} / \mathrm{ccm}]$
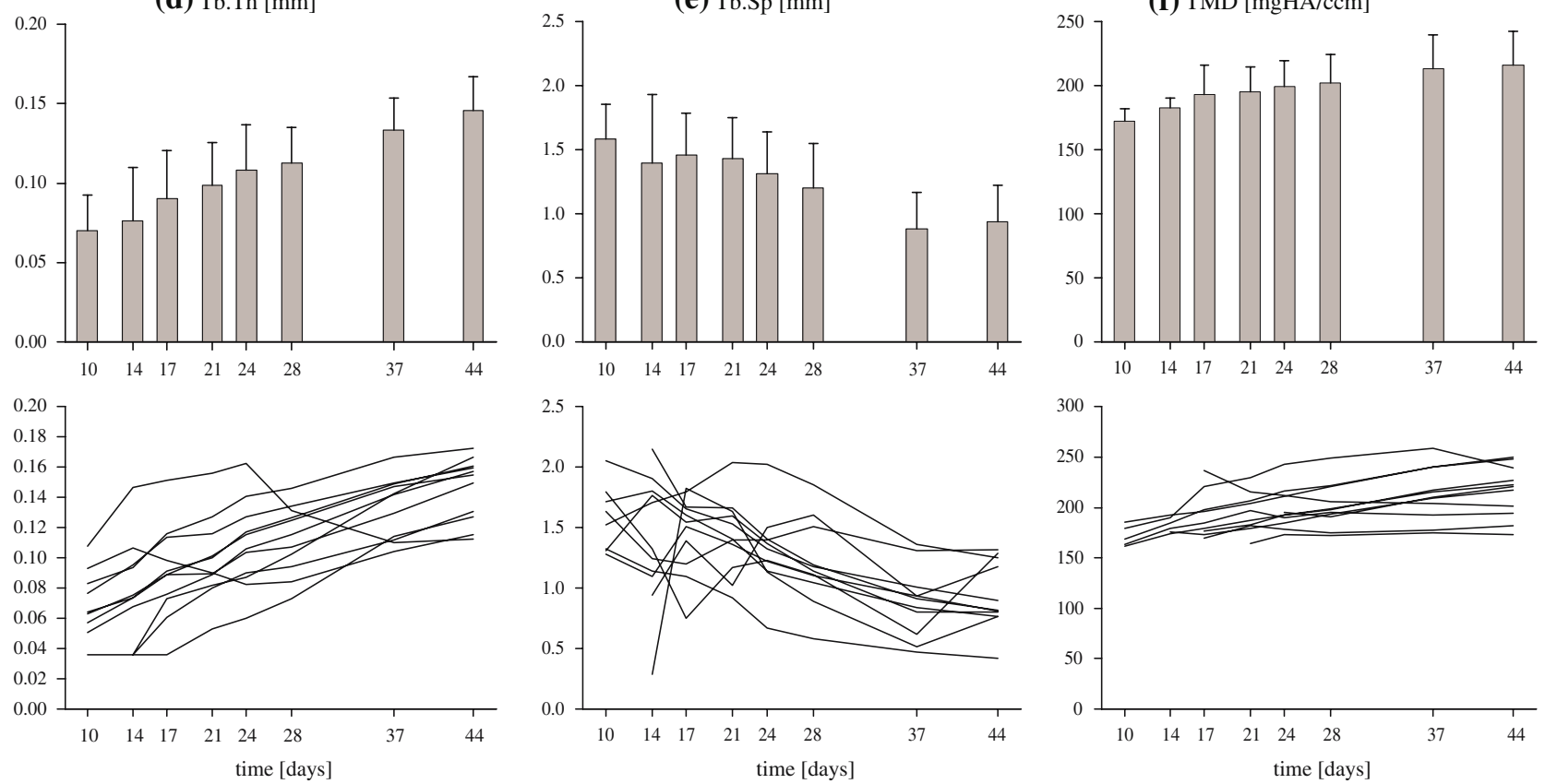

FIGURE 3. Results from full morphometric $\mu \mathrm{CT}$ analysis. Pooled (top) and individual (bottom) data from 11 samples: (a) bone volume density, (b) bone surface-to-volume ratio, (c) structure model index, (d) trabecular thickness, (e) trabecular spacing, and (f) tissue mineral density.

surface antigen expression and selective differentiation this cell isolate was referred to as hMSCs in this study.

From the total of 15 constructs (three vials each containing five constructs), which were scanned from day 7 through day 44, 11 constructs were well fixed in place for the whole culture period and, therefore, could be easily used for repetitive imaging analysis. Trabecular bone-like structures were tissue engineered
(Figs. 1 and 2). Pooled data illustrated a steady increase of average $\mathrm{BV} / \mathrm{TV}$ over time, as intuitively expected and corroborating previous reports (Fig. 3a). ${ }^{4}$ Large standard deviations were observed, although particular care was taken to standardize the experimental steps by using the same operator, the same batch of scaffolds, and the same course of cell seeding, cell number, medium supply, and imaging. 

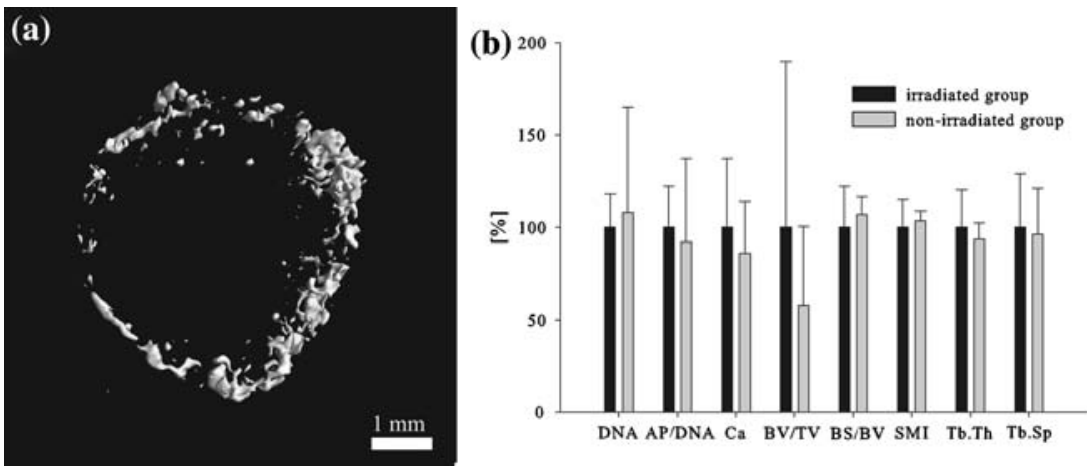

FIGURE 4. Effect of $\mu \mathrm{CT}$ imaging on cell performance. (a) Mineralized tissue volume of a formerly non-irradiated control sample at day 28 as imaged using $\mu \mathrm{CT}$. Compare to scans of monitored samples at day 28 in Fig. 1. (b) Quantitative comparison of irradiated group to non-irradiated control group regarding biochemical assays (DNA, AP activity per DNA, Ca content) and morphological parameters (BV/TV, BS/BV, SMI, Tb.Th, Tb.Sp). All values given in percent and normalized to mean of irradiated group.

However, only the individual assessment of samples over time, avoiding destructive end-point data collection, revealed the different tissue deposition patterns for each sample. To our knowledge, this study presents for the first time detailed, quantitative data on the progression of bone-like tissue formation of individual samples (Fig. 3).

Bone-like tissue growth was visualized by superimposing $\mu \mathrm{CT}$ images taken from three consecutive time points (Fig. 2). Bridging of bone-like components and, therefore, structure development was observed with highest bone volume densities at the periphery of the scaffolds, as reported elsewhere for static cultures., ${ }^{4,13}$ In former studies the cell distribution, proliferation, and activity after static Matrigel-based seeding and DMEM-based seeding, respectively, onto salt-leached SF scaffolds was evaluated. ${ }^{11,34}$ A homogeneous cell distribution throughout the scaffold was observed within pore sizes ranging between 112 and $700 \mu \mathrm{m}$. Therefore, the peripheral preference of the mineralized matrix deposition cannot be assumed to arise from initial cell distribution. Instead, limited ingrowth into the scaffold may be explained by different diffusion access for nutrition and gas, or inhibited cell migration to the center among samples. Diffusion could have been blocked in some cases by the initial scaffold geometry or cellular sheets occluding the pore's interconnectivity $^{4,14}$ and might not necessarily reflect differences in the osteogenic potential but rather differences in scaffold homogeneity. Image-guided optimization could possibly be developed into a useful tool to improve protocols resulting in the homogenous formation of bone-like tissue. In spite of the heterogeneous tissue formation process among the samples, evidence was demonstrated that initial BV was not predictive for overall bone volume after 44 days of culture (Figs. 1-3). This indicates the need for a noninvasive imaging approach to determine the best time for sample harvesting or intervention.
Mean bone surface-to-volume ratio (BS/BV) dropped throughout the culture period (from 80.0 to $26.1 \mathrm{~mm}^{-1}$, Fig. 3b). An explanation could be the deposition of several small seeding sites at the beginning. With progression of tissue culture, mineralized clusters merged, resulting in fewer particles, but larger particle volumes and, therefore, decreasing their surface-to-volume ratio. The decreasing variation in $\mathrm{BS} / \mathrm{BV}$ over time also indicated a biological control process aiming at a certain bone surface-to-volume ratio. This was corroborated by the course of the $\mathrm{BS} / \mathrm{BV}$ ratio for individual samples (Fig. 3b). These samples, all starting with different $\mathrm{BS} / \mathrm{BV}$ at day 10 , resulted in a common value of approximately $26 \mathrm{~mm}^{-1}$. Further studies are needed to detail the absolute value of $26 \mathrm{~mm}^{-1}$ and its variation dependent on issues such as scaffold properties, medium composition, donor or chemical, and physical stimulation.

The decrease in SMI from 3.2 to 2.6 indicated a structure development towards rods and plates from an initially more sphere-like structure. An explanation for the initially higher SMI are the new appearing bone-like clusters which are sphere-like and predominant in the beginning of the culture. With progression of the culture the established bone-like clusters grow and are geared to the surface of the scaffold. Accordingly, they tend to form rod- and plate-like structures. But the extrapolation of the monitoring suggests a further decrease in SMI. It is most likely, that the structure of the scaffold influences directly the final SMI of the deposited bone-like tissue.

Trabecular thickness increased towards a mean of $0.146 \mathrm{~mm}$. The varying values for Tb.Sp as they appear for the individual data could appear from either predominant newly formed clusters (Tb.Sp suddenly decreases) or merging of clusters, which were close to each other ( $\mathrm{Tb} . \mathrm{Sp}$ suddenly increases).

Mean tissue mineral density determined within the defined BV increased linearly between day 10 and day 
TABLE 1. Comparing morphometric indices of in vitro-engineered bone-like tissue to human trabecular bone ${ }^{9}$.

\begin{tabular}{|c|c|c|c|c|c|c|}
\hline \multirow[b]{2}{*}{ Index } & \multicolumn{3}{|c|}{ In vitro-engineered bone-like tissue at day 44} & \multicolumn{3}{|c|}{ Human biopsies } \\
\hline & Mean & Min & Max & Mean & Min & Max \\
\hline $\mathrm{BV} / \mathrm{TV}(\%)$ & 10 & 2 & 26 & 14 & 4 & 48 \\
\hline $\mathrm{BS} / \mathrm{BV}\left(\mathrm{mm}^{-1}\right)$ & 26 & 20 & 38 & 20 & 7 & 34 \\
\hline Tb.Th (mm) & 0.146 & 0.112 & 0.172 & 0.147 & 0.082 & 0.284 \\
\hline Tb.Sp (mm) & 0.937 & 0.422 & 1.317 & 0.742 & 0.454 & 1.308 \\
\hline SMI (1) & 2.6 & 2.2 & 3.4 & 1.5 & -0.7 & 2.9 \\
\hline
\end{tabular}

44 (Fig. 3f), demonstrating the continuous mineralization of the tissue. The deviations in tissue mineral density between the samples were rather small. At this point monitoring systems enable the presentation of new parameters like tissue mineralization rate, which in this study is $\frac{d T M D}{d t}=1 \frac{\mathrm{mgHA}}{\mathrm{ccm} \cdot \mathrm{day}}$. To exclude partial volume effects, which make voxels around the volume's surface appear in a slightly wrong gray value, two voxels were peeled from the surface before determination of the tissue mineral density, as recommended by the $\mu \mathrm{CT}$ manufacturer. Since for this study resolution $(36 \mu \mathrm{m})$ was rather coarse compared to mean trabecular thicknesses $(72-146 \mu \mathrm{m})$, a significant amount of the bone volume was removed due to peeling. Therefore, only general trends but no exact data on TMD can be reported. To make TMD determination a powerful tool in the future, e.g. to study bone formation and mineralization at the surface of the tissue in more detail, resolution has to be further improved while $\mu \mathrm{CT}$ measurement times have to remain brief, to not keep the tissue out of the incubator for too long.

Based on detailed quantification, the engineered tissues' morphology could be compared to human biopsy data $\left(\right.$ Table $1^{9}$ ). At day $44, \mathrm{BV} / \mathrm{TV}$ of the tissueengineered constructs ranged between $2 \%$ and $26 \%$ and therefore well within physiological $\mathrm{BV} / \mathrm{TV}$ values for human trabecular bone, which range between $4 \%$ and $48 \%$ depending on the anatomical site. Concerning $\mathrm{BS} / \mathrm{BV}$ (average value of $26 \mathrm{~mm}^{-1}$ in vitro), human bone biopsies measurements revealed values between 7 and $34 \mathrm{~mm}^{-1}$ depending on the harvest site. Compared to the SMI of human trabecular bone, which is approximately 2.1 at the lumbar spine and 0.4 at the femoral head, the SMI within this study is still rather high. The achieved average of $0.147 \mathrm{~mm}$ for Tb.Th is identical to human physiological values for trabecular bone (mean Tb.Th in trabecular bone from iliac crest, lumbar spine, femoral head, and calcaneal core: $\mathrm{Tb} . \mathrm{Th}=0.147 \mathrm{~mm}$ ). At the end of the culture period the trabecular spacing range in vitro $(0.43-1.32 \mathrm{~mm})$ matched well with the human physiological range $(0.45-1.31 \mathrm{~mm})$. However, concerning all morphological evaluations performed in this in vitro study, it has to be kept in mind, that the samples' distribution of mineralization was not homogeneous throughout the constructs. Even when mineralization is inhomogeneous, BS/BV, SMI, and Tb.Th are the same locally as they are globally. This is not the case for $\mathrm{BV} / \mathrm{TV}$ and Tb.Sp. Nevertheless, BV/TV and Tb.Sp are important parameters to judge on the global quality of the engineered tissue. To be able to quantitatively monitor the mineralization homogeneity, the standard deviation of Tb.Sp within each sample might be an appropriate index in future studies.

The impact of irradiation on osteogenic cell performance was assessed. Effects of ionizing irradiation on gene expression (e.g. Telomerase, c-myc, c-jun, IL6) and DNA strand breaks in human cells were reported from doses in the order of $0.1 \mathrm{mGy}$ or larger and after 1-14 days. ${ }^{3,6,8,24,28}$ Depending on exposure time, $\mu \mathrm{CT}$ as used in the present study exposes specimens to X-ray doses in the order of 0.1-1 Gy (data not shown) and, therefore, risk is present. The biochemical evaluations completed here are insufficient to assess this risk e.g. of malignic transformations. ${ }^{27}$ Furthermore, multiple exposures as used in this study further enhance potential pathological cell alterations. We confined the biochemical assessment to cellular osteogenic performance, when exposed to X-ray. In this study, cellular proliferation and calcium deposition were not influenced after seven $\mu \mathrm{CT}$ cycles, a finding corroborating previous reports. ${ }^{4}$ However, since DNA content was only measured at one time-point and showed large standard deviation, the presented data on DNA content provide a low statistical power for finally discerning potential differences in cell proliferation due to $\mu \mathrm{CT}$ monitoring. Also morphometrical development of the tissue was not significantly influenced by irradiation. The goal of this study was not to demonstrate that the integral use of $\mu \mathrm{CT}$ can be generally recognized as a safe tool. Eventual use of $\mu \mathrm{CT}$ or the assessment of implants must be accompanied by genotox studies and other toxicological evaluations. However, the biochemical data suggested that an analysis of temporal and spatial mineralization events was possible without inducing alterations in osteogenic patterns, an encouraging first step in this process. 
Besides the irradiation dose as a limiting factor also imaging time and imaging resolution are crucial parameters for clinical applications. With the prospective development of faster $\mu \mathrm{CT}$ systems, imaging times will get shorter. On the one hand, this would enable to shorten the samples' time outside the incubator and, therefore, be less disturbing to the tissue. On the other hand, imaging resolution could get higher, which allows a more detailed tissue analysis, i.e. regarding TMD.

The results of this study demonstrated the feasibility of monitoring and quantifying the formation of in vitro-engineered bone-like tissue from hMSC by the integral use of $\mu \mathrm{CT}$. Trabecular bone-like tissue was grown, visualized in situ, and its morphology was found to lie well within human physiological ranges. To make general conclusions about bone formation in situ from the detailed individual quantification, sample numbers are probably too low. But this setup enables further investigations of phenomena like final surface-to-volume ratio or SMI development. In the future, individual monitoring of morphology and mineralization over time should enable feedback loops with controlled bioreactors and the generation of homogenously mineralized implants. We are aiming for the tuning of certain morphometrical indices towards predetermined values during the culture. Furthermore, this process can result in advanced test systems, detailing drug action on tissue performance. However, detailed studies on the genotoxicological potential for the described setting are needed, before embarking into a $\mu \mathrm{CT}$ based and image guided future of bone tissue engineering.

\section{ACKNOWLEDGMENTS}

Financial support from ETH Zurich (TH 26.04-1), the Association for Orthopedic Research (AFOR), and the NIH Tissue Engineering Resource Center are greatly appreciated. We thank Dr. Martin Stauber for help in AVS illustration, Trudel Inc. for silk cocoons, and Wyeth Biopharmaceuticals for BMP-2 supply.

\section{REFERENCES}

\footnotetext{
${ }^{1}$ Alsberg, E., E. E. Hill, and D. J. Mooney. Craniofacial tissue engineering. Crit. Rev. Oral Biol. Med. 12:64-75, 2001.

${ }^{2}$ Asakura, A., M. Komaki, and M. Rudnicki. Muscle satellite cells are multipotential stem cells that exhibit myogenic, osteogenic, and adipogenic differentiation. Differentiation 68:245-253, 2001.
}

${ }^{3}$ Beetz, A., G. Messer, T. Oppel, D. van Beuningen, R. U. Peter, and P. Kind. Induction of interleukin 6 by ionizing radiation in a human epithelial cell line: control by corticosteroids. Int. J. Radiat. Biol. 72:33-43, 1997.

${ }^{4}$ Cartmell, S., K. Huynh, A. Lin, S. Nagaraja, and R. Guldberg. Quantitative microcomputed tomography analysis of mineralization within three-dimensional scaffolds in vitro. J. Biomed. Mater. Res. A 69:97-104, 2004. ${ }^{5}$ Demarteau, O., D. Wendt, A. Braccini, M. Jakob, D. Schafer, M. Heberer, and I. Martin. Dynamic compression of cartilage constructs engineered from expanded human articular chondrocytes. Biochem. Biophys. Res. Commun. 310:580-588, 2003.

${ }^{6}$ Enomoto, A., N. Suzuki, Y. Kang, K. Hirano, Y. Matsumoto, J. Zhu, A. Morita, Y. Hosoi, K. Sakai, and H. Koyama. Decreased c-Myc expression and its involvement in X-ray-induced apoptotic cell death of human T-cell leukaemia cell line MOLT-4. Int. J. Radiat. Biol. 79:589600, 2003.

${ }^{7}$ Freyria, A. M., Y. Yang, H. Chajra, C. F. Rousseau, M. C. Ronziere, D. Herbage, and A. J. El Haj. Optimization of dynamic culture conditions: effects on biosynthetic activities of chondrocytes grown in collagen sponges. Tissue Eng. 11:674-684, 2005.

${ }^{8}$ Hallahan, D. E., E. Dunphy, J. Kuchibhotla, A. Kraft, T. Unlap, and R. R. Weichselbaum. Prolonged c-jun expression in irradiated ataxia telangiectasia fibroblasts. Int. J. Radiat. Oncol. Biol. Phys. 36:355-360, 1996.

${ }^{9}$ Hildebrand, T., A. Laib, R. Müller, J. Dequeker, and P. Rüegsegger. Direct three-dimensional morphometric analysis of human cancellous bone: microstructural data from spine, femur, iliac crest, and calcaneus. J. Bone Miner. Res. 14:1167-1174, 1999.

${ }^{10}$ Hildebrand, T., and P. Ruegsegger. Quantification of bone microarchitecture with the structure model index. Comput. Methods Biomech. Biomed. Eng. 1:15-23, 1997.

${ }^{11}$ Hofmann, S., H. Hagenmuller, A. M. Koch, R. Muller, G. Vunjak-Novakovic, D. L. Kaplan, H. P. Merkle, and L. Meinel. Control of in vitro tissue-engineered bone-like structures using human mesenchymal stem cells and porous silk scaffolds. Biomaterials 28:1152-1162, 2007.

${ }^{12}$ Hollinger, J. O., S. Winn, and J. Bonadio. Options for tissue engineering to address challenges of the aging skeleton. Tissue Eng. 6:341-350, 2000.

${ }^{13}$ Ishaug, S. L., G. M. Crane, M. J. Miller, A. W. Yasko, M. J. Yaszemski, and A. G. Mikos. Bone formation by threedimensional stromal osteoblast culture in biodegradable polymer scaffolds. J. Biomed. Mater. Res. 36:17-28, 1997.

${ }^{14}$ Ishaug-Riley, S. L., G. M. Crane-Kruger, M. J. Yaszemski, and A. G. Mikos. Three-dimensional culture of rat calvarial osteoblasts in porous biodegradable polymers. Biomaterials 19:1405-1412, 1998.

${ }^{15}$ Karageorgiou, V., M. Tomkins, R. Fajardo, L. Meinel, B. Snyder, K. Wade, J. Chen, G. Vunjak-Novakovic, and D. L. Kaplan. Porous silk fibroin 3-D scaffolds for delivery of bone morphogenetic protein-2 in vitro and in vivo. J. Biomed. Mater. Res. A 78:324-334, 2006.

${ }^{16}$ Martin, I., D. Wendt, and M. Heberer. The role of bioreactors in tissue engineering. Trends Biotechnol. 22:80-86, 2004.

${ }^{17}$ Meinel, L., R. Fajardo, S. Hofmann, R. Langer, J. Chen, B. Snyder, G. Vunjak-Novakovic, and D. Kaplan. Silk implants for the healing of critical size bone defects. Bone 37:688-698, 2005. 
${ }^{18}$ Meinel, L., S. Hofmann, O. Betz, R. Fajardo, H. P. Merkle, R. Langer, C. H. Evans, G. Vunjak-Novakovic, and D. L. Kaplan. Osteogenesis by human mesenchymal stem cells cultured on silk biomaterials: comparison of adenovirus mediated gene transfer and protein delivery of BMP-2. Biomaterials 27:4993-5002, 2006.

${ }^{19}$ Meinel, L., V. Karageorgiou, R. Fajardo, B. Snyder, V. Shinde-Patil, L. Zichner, D. Kaplan, R. Langer, and G. Vunjak-Novakovic. Bone tissue engineering using human mesenchymal stem cells: effects of scaffold material and medium flow. Ann. Biomed. Eng. 32:112-122, 2004.

${ }^{20}$ Meinel, L., V. Karageorgiou, S. Hofmann, R. Fajardo, B. Snyder, C. Li, L. Zichner, R. Langer, G. Vunjak-Novakovic, and D. L. Kaplan. Engineering bone-like tissue in vitro using human bone marrow stem cells and silk scaffolds. J. Biomed. Mater. Res. A 71:25-34, 2004.

${ }^{21}$ Müller, R., T. Hildebrand, and P. Rüegsegger. Non-invasive bone biopsy: a new method to analyse and display the three-dimensional structure of trabecular bone. Phys. Med. Biol. 39:145-164, 1994.

${ }^{22}$ Müller, R., and P. Rüegsegger. Micro-tomographic imaging for the nondestructive evaluation of trabecular bone architecture. Stud. Health Technol. Inform. 40:61-79, 1997.

${ }^{23}$ Nazarov, R., H. J. Jin, and D. L. Kaplan. Porous 3-D scaffolds from regenerated silk fibroin. Biomacromolecules 5:718-726, 2004.

${ }^{24}$ Neuhof, D., A. Ruess, F. Wenz, and K. J. Weber. Induction of telomerase activity by irradiation in human lymphoblasts. Radiat. Res. 155:693-697, 2001.

${ }^{25}$ Pittenger, M. F., A. M. Mackay, S. C. Beck, R. K. Jaiswal, R. Douglas, J. D. Mosca, M. A. Moorman, D. W. Simonetti, S. Craig, and D. R. Marshak. Multilineage potential of adult human mesenchymal stem cells. Science 284:143147, 1999.
${ }^{26}$ Risbud, M. V., and M. Sittinger. Tissue engineering: advances in in vitro cartilage generation. Trends Biotechnol. 20:351-356, 2002.

${ }^{27}$ Ritman, E. L. Micro-computed tomography-current status and developments. Annu. Rev. Biomed. Eng. 6:185-208, 2004.

${ }^{28}$ Rogakou, E. P., C. Boon, C. Redon, and W. M. Bonner. Megabase chromatin domains involved in DNA doublestrand breaks in vivo. J. Cell Biol. 146:905-916, 1999.

${ }^{29}$ Rüegsegger, P., B. Koller, and R. Müller. A microtomographic system for the nondestructive evaluation of bone architecture. Calcif. Tissue Int. 58:24-29, 1996.

${ }^{30}$ Seifert, B., G. Mihanetzis, T. Groth, W. Albrecht, K. Richau, Y. Missirlis, D. Paul, and G. von Sengbusch. Polyetherimide: a new membrane-forming polymer for biomedical applications. Artif. Organs 26:189-199, 2002.

${ }^{31}$ Sikavitsas, V. I., G. N. Bancroft, J. J. Lemoine, M. A. Liebschner, M. Dauner, and A. G. Mikos. Flow perfusion enhances the calcified matrix deposition of marrow stromal cells in biodegradable nonwoven fiber mesh scaffolds. Ann. Biomed. Eng. 33:63-70, 2005.

${ }^{32}$ Singh, H., S. H. Teoh, H. T. Low, and D. W. Hutmacher. Flow modelling within a scaffold under the influence of uni-axial and bi-axial bioreactor rotation. J. Biotechnol. 119:181-196, 2005.

${ }^{33}$ Vunjak-Novakovic, G., L. Meinel, G. Altman, and D. Kaplan. Bioreactor cultivation of osteochondral grafts. Orthod. Craniofac. Res. 8:209-218, 2005.

${ }^{34}$ Wang, Y., U. J. Kim, D. J. Blasioli, H. J. Kim, and D. L. Kaplan. In vitro cartilage tissue engineering with $3 \mathrm{D}$ porous aqueous-derived silk scaffolds and mesenchymal stem cells. Biomaterials 26:7082-7094, 2005.

${ }^{35}$ Washburn, N. R., M. Weir, P. Anderson, and K. Potter. Bone formation in polymeric scaffolds evaluated by proton magnetic resonance microscopy and X-ray microtomography. J. Biomed. Mater. Res. A 69:738-747, 2004. 